\title{
KRUKENBERG TUMORS FROM BREAST CANCER - LITERATURE REVIEW
}

\author{
Nicolae BACALBASA ${ }^{1,2,3 凶}$, Irina BALESCU ${ }^{4,5}$, Mihaela VILCU ${ }^{1,6}$, loana HALMACIU, \\ Camelia C. DIACONU ${ }^{1,8}$, Simona DIMA ${ }^{3}$, Iulian BREZEAN ${ }^{1,6}$
}

1 „Carol Davila“ University of Medicine and Pharmacy, Bucharest, Romania

${ }^{2}$ Department of Obstetrics and Gynecology, „I. Cantacuzino“ Clinical Hospital, Bucharest, Romania

${ }^{3}$ Department of Visceral Surgery, Center of Excellence in Translational Medicine „Fundeni“ Clinical Institute, Bucharest, Romania

${ }^{4}$ Department of Surgery, „Ponderas“ Academic Hospital, Bucharest, Romania

5 „Carol Davila“ University of Medicine and Pharmacy, Bucharest, Romania

${ }^{6}$ Department of Visceral Surgery, „I. Cantacuzino“ Clinical Hospital, Bucharest, Romania

7 Department of Anatomy, „George Emil Palade“ University of Medicine, Pharmacy, Science and Technology, Targu Mures, Romania

${ }^{8}$ Department of Internal Medicine, Clinical Emergency Hospital of Bucharest, Bucharest, Romania

Received 18 Febr 2020, Accepted 09 Apr 2020

https://doi.org/10.31688/ABMU.2020.55.2.16

\section{Abstract}

Krukenberg tumors are ovarian metastases from different malignancies, most often originating from the gastrointestinal tract. However, in rare cases, other primary tumors, even with extra-abdominal location, might lead to the development of such lesions. Neither the mechanism of development, prognostic significance or therapeutic strategy are not clearly defined so far. It seems that these lesions are more frequently encountered in patients with BRCA1/2 mutations. Most often, Krukenberg tumors are bilateral lesions associated with ascites and with firm areas at the level of the ovarian surface. This paper aims to review existing data regarding Krukenberg tumors from breast cancer.

Keywords: Krukenberg tumors, breast cancer, prognosis.

\section{Résumé}

Les tumeurs de Krukenberg à partir du cancer du sein - revue de la littérature

Les tumeurs de Krukenberg sont des métastases ovariennes de différentes tumeurs malignes, provenant le plus souvent du tractus gastro-intestinal. Cependant, dans de rares cas, d'autres tumeurs primaires, même avec une localisation extra-abdominale, peuvent conduire au développement de telles lésions. Ni le mécanisme de développement, ni la signification pronostique ni la stratégie thérapeutique ne sont clairement définis à ce jour. Il semble que ces lésions soient plus fréquemment rencontrées chez les patients porteurs de mutations BRCA1/2. Le plus souvent, les tumeurs de Krukenberg sont des lésions bilatérales associées à une ascite et à des zones fermes au niveau de la surface ovarienne. Le but de cet article est de passer en 
revue les données existantes concernant les tumeurs de Krukenberg du cancer du sein.

Mots-clés: tumeurs de Krukenberg, cancer du sein, pronostic.

\section{INTRODUCTION}

Defined by the presence of tumoral cells at the level of the ovaries, Krukenberg tumors usually originate from gastrointestinal metastases and represent one of the most relevant arguments in favour of the "seed and soil" theory, which has been proposed by Paget in $1889^{1}$. According to this theory, specific malignancies have predilection for specific sites, purely independent from anatomical or vascular factors.

When it comes to ovarian pathology, it has been widely demonstrated that a significant number of cases diagnosed with intra-abdominal malignancies, especially gastro-intestinal malignancies, will lead to the appearance of ovarian metastases ${ }^{2}$. Since most often ovarian metastases occur in patients with gastric cancer, certain authors considered that this notion should be used only to refer to this particular situation, while other authors consider that any metastatic involvement of the ovaries should be considered as Krukenberg tumors, irrespective of the origin of the primary tumor ${ }^{3-6}$. In rare cases, extra-abdominal malignancies, such as breast cancer, might lead to the appearance of Krukenberg tumors. However, neither the mechanism of development, prognostic significance or therapeutic strategy are not clearly defined so far. Most often, Krukenberg tumors are bilateral lesions associated with ascites and with firm areas at the level of the ovarian surface ${ }^{7-9}$.

\section{EPIDEMIOLOGY OF BREAST CANCER KRUKENBERG TUMORS}

It is estimated that Krukenberg tumors represent up to $28 \%$ of all ovarian tumors, primary breast cancer being responsible for up to $31 \%$ of cases, the most commonly involved histopathological subtype being represented by ductal invasive carcinoma and lobular carcinoma ${ }^{8,10}$. Interestingly, in a study conducted by Lumb and Mackenzie, the authors reported the fact that $29.4 \%$ of breast cancer patients submitted to prophylactic oophorectomy had histopathological proofs of ovarian metastases, while Webb et al demonstrated that up to $31 \%$ of cases might associate this pathology ${ }^{11,12}$.

Most often, these tumors are bilateral and occur in women younger than 45 years of age ${ }^{10}$. The young age at the diagnosis of these lesions has a double explanation: first of all, breast cancer is frequently more common in younger patients, while the second reason is related to a higher tropism of the ovaries for metastatic cells during the reproductive age ${ }^{13}$.

As for the moment of development of Krukenberg tumors, Le Bouedec et al reported that this interval ranged between 1.5 and 12 years, while Gagnon et al reported a median interval of 11.5 months and a median overall survival of 16 months after Krukenberg tumor diagnosis ${ }^{14,15}$.

An interesting situation is when the initial diagnosis is of the ovarian tumor and the primary malignancy is diagnosed only later. Therefore, in the research conducted by Ho et al, the case of a 62-year-old patient who was initially diagnosed with a large ovarian mass was presented; at that moment, a total hysterectomy with bilateral adnexectomy were performed, the histopathological and immunohistochemical studies confirming the metastatic origin of the lesion; finally, the histopathological diagnosis was of a metastatic lobular carcinoma of the breast. Although at clinical examination no tumor was palpable at the level of breasts, the performed mammography demonstrated the presence of a suspect lesion measuring $6 / 4 \mathrm{~mm}$, which was biopsied, the presence of a lobular carcinoma being confirmed ${ }^{16}$.

\section{ROUTE OF DISSEMINATION FOR MALIGNANT CELLS}

Since the possibility of ovarian metastases with different origins has been demonstrated, attention was focused on identifying the routes of spread which are responsible for the development of such metastases $^{17,18}$. One of the most widely approved theories considers that malignant emboli from the primary tumor block the peritumoral lymph nodes, forcing in this way the lymphatic flow to take a descendent direction. This theory is supported by the fact that most often tumoral involvement of the ovary is seen at the level of the cortex and the hilum and only in rare cases at the level of the ovarian surface, ${ }^{9,19}$.

Another theory, which tried to explain the development of Krukenberg tumors in breast cancer patients, is related to the presence of $\mathrm{BRCA} 1 / 2$ mutation ${ }^{20}$.

\section{Histopathological SUBTyPes OF BREAST CANCER ASSOCIATED WITH KRUKENBERG TUMORS}

As for the histopathological types of breast carcinomas more frequently associated with Krukenberg 
tumors, it seems that invasive ductal carcinoma is most commonly encountered ${ }^{15,21}$.

One of the largest studies conducted on this issue included 14 patients diagnosed with Krukenberg tumors from breast cancer; among these cases, there were 4 cases with invasive ductal carcinoma, 4 cases with invasive lobular carcinoma, 4 cases with adenocarcinoma not otherwise specified, 2 cases of ductal and lobular carcinomas and other 2 cases with unspecified carcinomas; in $87 \%$ cases, the Krukenberg tumors were bilateral, having a mean diameter of 8 $\mathrm{cm}$. Further on, the diagnosis was established by histopathological and immunohistochemical studies ${ }^{22}$.

When it comes to the differential diagnosis of Krukenberg tumors with breast cancer origin, most frequently a Brenner tumor should be excluded; however, the bilaterality of the lesions, in association with the presence of vascular emboli and with the absence of omental deposits and of the transition from benign to malignant epithelium, might orientate the diagnosis ${ }^{23-25}$

\section{ROLE OF SURGERY FOR KRUKENBERG TUMORS ORIGINATING FROM BREAST CANCER}

The role of surgery and the influence of Krukenberg tumors on the long-term outcomes of breast cancer patients have been usually investigated in larger studies, conducted on the issue of Krukenberg tumors with different origins, due to the relatively low number of such cases.

For example, in a study conducted by Jiang et al, on 54 cases diagnosed with Krukenberg tumors, there were 3 cases initially diagnosed with breast cancer. All 3 cases were submitted to adnexectomy, two of them died at 31.7 months and 48.2 months respectively, while the third one was still alive at the 48 months follow-up. Moreover, the authors underlined the fact that at a median follow-up of 30 months, $79.6 \%$ of all cases died because of disease progression, the median survival being of 17.8 months. These data enable us to consider that, although they can be considered as a sign of the systemic disease, Krukenberg tumors from breast cancer seem to be associated with a better outcome when compared to other primary tumors ${ }^{26}$.

Another study, conducted on the theme of clinical and prognostic factors in patients with Krukenberg tumors, was published by the Chinese authors conducted by Wu et al in 2015; the authors conducted a study on 128 patients diagnosed with Krukenberg tumors between 1990 and 2010, eight of them presenting primary breast cancer ${ }^{13}$. The authors reported a median overall survival of 16 months, which was significantly influenced by the origin of the primary tumor; therefore, patients with Krukenberg tumors originating from breast cancer reported a significantly better mean overall survival when compared to cases initially diagnosed with gastric cancer ( 31 months versus 11 months, $\mathrm{p}<0.0001$ ). In the meantime, the authors underlined the fact that breast cancer patients reported the best outcomes after metastasectomy when compared to all the other subtypes; therefore, breast cancer patients reported a median survival of 31 months, followed by cases with colorectal cancer - with a mean overall survival of 21.5 months and gastric cancer - with a mean overall survival of 11 months. This fact was explained by the authors through the observation that breast cancer usually associates a better long-term outcome when compared to gastro-intestinal cancers, especially when compared to gastric cancer, which is usually diagnosed in more advanced stages of the disease; the authors underlined the fact that gastric cancer is also associated with poorer performance status and anaemia, inducing in this way a poorer long-term outcome. Other prognostic factors were related to the time of diagnosis (synchronous lesions being associated with poorer outcomes when compared to metachronous lesions) and to the presence of extra-ovarian metastatic disease (therefore, the presence of extra-ovarian lesions is associated with significantly poorer outcomes when compared to cases presenting ovarian limited disease). Moreover, the multivariate analysis demonstrated that synchronous lesions, presence of pelvic invasion, ascites and the absence of surgical treatment were associated with poorer outcomes $^{13}$.

\section{Conclusions}

Though not as common as in gastrointestinal cancers, the Krukenberg tumors from breast cancer might be encountered. Although multiple mechanisms have been proposed so far, the development of these lesions is poorly understood; however, it seems that these lesions are more frequently encountered in patients with BRCA1/2 mutations. When it comes to the therapeutic strategy in such cases and to the prognostic factors, it seems that the absence of extra-ovarian diseases, as well as the association of radical surgery, might improve the long-term outcomes.

\section{Author contributions:}

I. B. and M.V. conceived the original draft preparation. N.B. and I. B. were responsible for conception and design of the review. I.H. and S.D. were responsible for the data acquisition. C.C.D. was responsible for the collection and assembly of the articles/published data, and their 
inclusion and interpretation in this review. All authors contributed to the critical revision of the manuscript for valuable intellectual content. All authors have read and agreed to the published version of the manuscript.

\section{Compliance with Ethics Requirements:}

„The authors declare no conflict of interest regarding this article"

\section{Acknowledgements:}

„This work was supported by the project entitled "Multidisciplinary Consortium for Supporting the Research Skills in Diagnosing, Treating and Identifying Predictive Factors of Malignant Gynecologic Disorders", project number PN-III-P1-1.2-PCCDI2017-0833."

\section{References}

1. Paget $\mathrm{S}$. The distribution of secondary growths in cancer of the breast. Cancer Metastasis Rev. 1989;8:98-101.

2. Ginghina $\mathrm{O}$, Negrei $\mathrm{C}$, Hudita $\mathrm{A}$, et al. In vitro impact of some natural compounds on HT-29 colorectal adenocarcinoma cells. Farmacia. 2017;65(6):947-953.

3. Jeung YJ, Ok HJ, Kim WG, Kim SH, Lee TH. Krukenberg tumors of gastric origin versus colorectal origin. Obstet Gynecol Sci. 2015;58:32-9.

4. Jiang R, Tang J, Cheng X, Zang RY. Surgical treatment for patients with different origins of Krukenberg tumors: outcomes and prognostic factors. Eur J Surg Oncol. 2009;35:92-7.

5. Peng W, Hua RX, Jiang R, et al. Surgical treatment for patients with Krukenberg tumor of stomach origin: clinical outcome and prognostic factors analysis. PloS One. 2013;8: e68227.

6. Kim HK, Heo DS, Bang YJ, Kim NK. Prognostic factors of Krukenberg's tumor. Gynecol Oncol. 2001;82:105-9.

7. Krukenberg F. Ueber das fibrosarcoma ovarii mucocellulare (carcinomatodes). Arch Gynecol Obstet. 1896;50(2):287-321.

8. Schlagenhaufer F. Ueber das metastatische ovarialcarcinom nach krebs des magens, darmes und anderer bauchorgane (Part 1 of 2). Gynecol Obstet Invest. 1902;15(4): 485-506.

9. Agnes A, Biondi A, Ricci R, Gallotta V, D’Ugo D, Persiani R. Krukenberg tumors: Seed, route and soil. Surg Oncol. 2017;26:438-45.

10. Kiyokawa T, Young RH, Scully RE. Krukenberg tumors of the ovary: a clinicopathologic analysis of 120 cases with emphasis on their variable pathologic manifestations. Am J Surg Pathol. 2006; 30: 277-99.

11. Lumb G, Mackenzie DH. The incidence of metastases in adrenal glands and ovaries removed for carcinoma of the breast. Cancer. 1959;12:521-6.

12. Web MJ, Decker DG, Mussey E. Cancer metastatic to the ovary: factors influencing survival. Obstet Gynecol. 1975;45:391-6

13. Wu F, Zhao X, Mi B et al. Clinical characteristics and prognostic analysis of Krukenberg tumor. Mol Clin Oncol. 2015;3:1323-8

14. Le Bouedec G, de Latour M, Levrel O, Dauplat J. Krukenberg tumors of breast origin. 10 cases. Presse Med. 1997;26:454-7.

15. Gagnon Y, Tetu B. Ovarian metastases of breast carcinoma. A clinicopathologic study of 59 cases. Cancer. 1989; 64: 892-8.

16. Ho GF, Chappell M, Robinson A. Invasive lobular carcinoma of the breast diagnosed from an ovarian tumor. Malays J Pathol. 2008;30:121-4.

17. Bratu OG, Cherciu AI, Bumbu A, et al. Retroperitoneal tumors - treatment and prognosis of tumor recurrence. Rev Chim. 2019;70(1):191-194.

18. Socea B, Nica AA, Bratu O, et al. Incidental finding of a sigmoid intussusception associated with rectal prolapse - a case report. Arch Balk Med Union. 2018;53(1):143-146.

19. Holtz F, Hart WR. Krukenberg tumors of the ovary: a clinicopathologic analysis of 27 cases. Cancer. 1982;50:2438-47.

20. Kauff ND, Barakat RR. Risk-reducing salpingo-oophorectomy in patients with germline mutations in BRCA1 or BRCA2. J Clin Oncol. 2007;25:2921-7.

21. Al Agha OM, Nicastri AD. An in-depth look at Krukenberg tumor: an overview. Arch Pathol Lab Med. 2006;130:1725-30.

22. Bennett JA, Young RH, Chuang AY, Lerwill MF. Ovarian metastases of breast cancers with signet ring cells: a report of 17 cases including 14 Krukenberg tumors. Int J Gynecol Pathol. 2018;37:507-15.

23. Powari M, Dey P, Gupta SK, Saha S. Metastatic tumors of the ovary: a clinico-pathological study. Indian J Pathol Microbiol. 2003;46:412-5.

24. Diaconu C, Balaceanu A, Bartos D. Venous thromboembolism in pregnant woman - a challenge for the clinician. Central European Journal of Medicine 2013;8(5):548-552.

25. Bratu OG, Marcu RD, Socea B, et al. Immunohistochemistry particularities of retroperitoneal tumors. Rev Chim. 2018;69(7):1813-1816.

26. Jiang R, Tang J, Cheng X, Zang RY. Surgical treatment for patients with different origins of Krukenberg tumors: outcomes and prognostic factors. Eur J Surg Oncol. 2009;35:92-7. 